\title{
Purdue dogged by misconduct claims
}

Purdue University has set up a third panel to look at allegations of research misconduct against nuclear engineer Rusi Taleyarkhan. The existence of the latest inquiry emerged when a congressional committee wrote to the university questioning the thoroughness of its earlier review. Now Purdue, based in West Lafayette, Indiana, faces an uphill task in convincing the wider scientific community that it is mounting a serious investigative effort, critics say.

Since 1999, Taleyarkhan has received more than \$780,000 from the Defense Advanced Research Projects Agency (DARPA) for work towards the goal of 'bubble fusion', in which energy-releasing fusion reactions are triggered by passing ultrasound through deuterated liquids ${ }^{1}$. In February, Purdue cleared him of misconduct after two inquiries ${ }^{2,3}$. But a third panel was set up in March following complaints to the inspector-general of the Office of Naval Research, which oversees DARPA grants.

Its existence came to light on $10 \mathrm{May}$, in a memo from the investigations and oversight subcommittee of the House Committee on Science and Technology, chaired by Brad Miller (Democrat, North Carolina). "I sincerely hope that the next inquiry will be conducted in a manner worthy of your great institution," Miller wrote to Purdue president Martin Jischke.

A subcommittee-staff memo sent with his letter alleges that Purdue's previous efforts on the issue were "not thorough", "never addressed the validity of the underlying research" and "did not follow" established procedures for investigating misconduct allegations. The criticisms are partly based on the subcommittee's analysis of internal Purdue documents that it requested in March.

According to the memo, these documents show that in March 2006, Purdue charged a

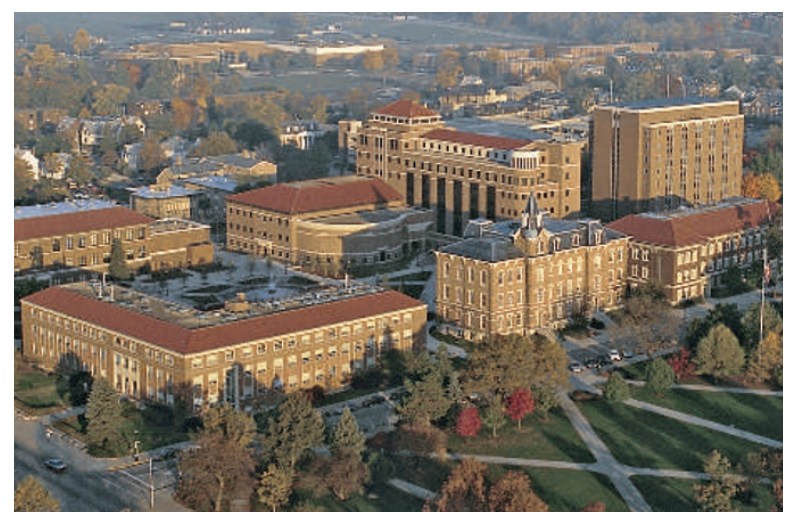

A third panel will probe bubble-fusion findings at Purdue University.

panel with determining the facts surrounding articles published in Nature and elsewhere that reported concerns over the validity of Taleyarkhan's research. This first panel reviewed a limited number of documents, interviewed only two professors inside Purdue, and concluded its work by recommending further interviews and examination of lab notebooks, the memo says. University officials then set up a second inquiry panel that, according to the memo, did not seem to follow the recommendations of the first, but instead solicited and examined a narrower set of allegations.

The memo reports that the second panel concluded that Taleyarkhan showed "what might be characterized most favorably as severe lack of judgment" when he participated in the preparation of a manuscript by a postdoc and a graduate student that claimed positive results for bubble fusion and did not name him as an author. Taleyarkhan then cited the work as "independent" confirmation of his own earlier research claims. The claim would not be accepted by the wider scientific community, the inquiry found. The memo says that the inquiry found Taleyarkhan had "abused his privilege as senior scientist” and placed the junior scientists in "precarious positions". But the inquiry concluded that no full-scale investigation into the possibility of misconduct or the underlying research was warranted and the university then cleared Taleyarkhan of wrongdoing in a press release.

Immediately after the release of Miller's letter and the accompanying memo, Purdue issued a statement saying that although it "could debate" some of its contents, the university would instead focus on its fresh inquiry.

Taleyarkhan's long time co-author, Richard Lahey of Rensselaer Polytechnic Institute in Troy, New York, took issue with the memo, saying that he had full confidence in Taleyarkhan's abilities and integrity and that the true story was one of "an exciting scientific discovery". He criticized congressional staff members for failing to contact him or Taleyarkhan's other co-authors as a part of their own inquiries.

Purdue's new inquiry is understood to be covering some of the ground omitted by earlier ones, including allegations that Taleyarkhan's work may be fraudulent, a concern first received by the university in June 2006. The new panel consists of unnamed panellists from the previous inquiries, because, Purdue says, these people are "familiar with the issues". In its statement, Purdue pledged to add one or more outside scientists to the panel.

\section{India struggles to find director for top research agency}

India's largest research agency has been without a permanent director for almost five months, prompting some observers to claim that science isn't high on the government's agenda.

The role of director of the Council of Scientific and Industrial Research (CSIR), which runs 37 laboratories staffed by more than 18,000 scientists, comes with the status of a government secretary. It became vacant last December when chemist Raghunath Mashelkar quit the post - and the hunt for a successor has got nowhere fast.

Science minister Kapil Sibal initially appointed Visveswaraiah Prakash, director of the CSIR's Central Food Technological Research Institute in Mysore, but he withdrew on health grounds. Maharaj Kishan Bhan, the government's biotechnology secretary, took temporary charge in January, but after eight weeks he passed the responsibility to Thirumalachari Ramasami, secretary of the Department of Science and Technology.

India's prime minister, Manmohan Singh, keeps saying the government gives priority to science, says Sri Krishna Joshi, director of the CSIR from 1991 to 1995 . "But one does not get the feeling he is serious, considering that the CSIR, of which he himself is president, has been headless for so long."

Scientists blame the declining prestige of public research as one reason for the failure to appoint a director. "Until a few years ago, the only way for a scientist to get noticed was by becoming a secretary to a scientific department," says Samir Brahmachari, who heads 
But that may not be enough to restore credibility in the university's process, says C. K. Gunsalus, a lawyer at the University of Illinois at Urbana-Champaign who specializes in research misconduct. "They need to completely reconstitute the process. Different panellists, including at least one external to the institution, are required to restore faith in their findings. It's the only way to close the matter."

Gunsalus says the case raises a broader issue of how officials respond to misconduct accusations. "There's an unwillingness to be embarrassed," she says. "People can make intuitive, but mistaken, decisions counter to the underlying interest, which is the integrity of the institution."

Purdue says that it will continue to adhere to its own policy and to federal guidelines. Responding to Purdue's statement, Taleyarkhan said: "I have confirmed my full and complete cooperation with the new inquiry to be introduced this year at Purdue and, in fact, welcome the opportunity to once again clear up the doubts raised in the press."

At Purdue, nuclear-engineering faculty expressed mixed feelings about the affair. Chan Choi, who chaired a fact-finding internal committee that looked into the authorship issues, says that institutional blunders should not overshadow the ample sound research performed at the university. "I think they have to make the charges clear and I think the committee's names should be known," he says. But he adds that the outside interest has provided an opportunity for the university to improve its procedure now: "That's a healthy message from Congress."

Eugenie Samuel Reich

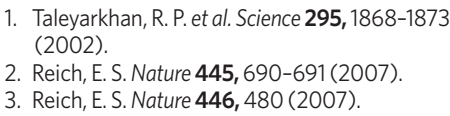

the CSIR's genomics institute in New Delhi. "Today, with opportunities to do good science outside the government, no brilliant scientist would want to be a secretary and be answerable to the parliament and all sorts of committees."

Scientists at the CSIR agree that it's a difficult job. During Mashelkar's eleven years as director, unions were banned and complaints from staff were rarely entertained. "The new director should be ready to deal with the thousands of complaints that have piled up," says one lab director who wants to remain anonymous.

K. S. Jayaraman

$\nabla$

BUBBLE FUSION

Find the back-story of Taleyarkhan's table-top fusion research online. www.nature.com/ news/bubblefusion

\section{Anger at 'unfit' museum design}

The directors of the Natural History Museum in London are under fire over plans to split parts of its world-renowned collection of biological specimens on a permanent basis. Some of the museum's curators are angry that plans for a new building to store the bulk of the museum's entomology and botany collections remain unaltered three years after being branded unfit for the purpose by museum staff.

Work has now started on the E73-million (US\$140-million) building for the Darwin Centre Phase Two, even though there won't be space to house all of the museum's 28 million insect specimens and 5.5 million plants. The structure will replace the previous Entomology Building, which was demolished in 2006: it had been impregnated with potentially cancer-causing naphthalene, which helped to preserve specimens.

"Our first gripe is that they wilfully destroyed a sound building without looking at the alternatives," says Henry Barlow, an entomologist who contributed some 30,000 specimens to the museum's collections and a member of Friends of the Natural History Museum, a group of donors and visitors that liaises with museum staff. Barlow accuses the museum of being more interested in winning architectural awards than properly

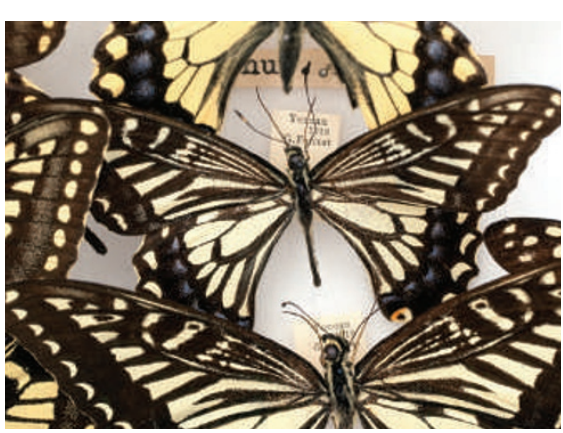

curating its collections.

Museum directors found that refurbishing the previous building was not costeffective, says the museum's head of collections, Mike Fitton. He says when the new building opens in 2009, it will offer better conditions for specimens, better research facilities and improved public access, so visitors can see the museum's research in action. "The collections have not lost out to architecture - they have lost to these three aspirations," he told Nature.

\section{"The public will get an} unprecedented insight into how the institution's painstaking taxonomic research is carried out."

The Friends of the Natural History Museum will meet with museum director Michael Dixon on 22 May to discuss the plans. "Some fairly pointed questions need to be asked," says Barlow.

Chief among these will be why the new storage facility, known as the 'cocoon' after its curving walls encased in an eight-storey glass box, will have only 3.4 kilometres of shelving for storing specimens, even though a 2001 report by the museum's trustees said that 4.6 kilometres of shelving was required.

Fitton says the museum commissioned a study at the

Safe storage of specimens such as those of the order Lepidoptera is a Natural History Museum concern. project's inception in 1999 to evaluate the idea of storing all the collections under one roof. But with the selected design, by Danish firm C. F. Møller Architects, this was considered impractical, and the 2004 unveiling of the design to museum workers was met with anger (see Nature 432, 659; 2004).

Researchers' fears for the collections are exacerbated by the fact that the specimens are currently being kept at the museum's overspill facility in Wandsworth, southwest London. Barlow says this building is prone to high humidity and is below the flood level of the nearby River Thames, but museum officials say conditions are first-class.

It remains unclear whether some specimens will stay in Wandsworth permanently after the new building opens, or whether space will be found elsewhere on the museum's main campus in central London. Of the 129,000 drawers in which the entomology collection currently sits, there will be room for 120,000 in the Darwin Centre, says Fitton. "We could have squeezed all the insects in but that would be silly," he says, because the collection is expected to grow by around $10 \%$ during the life of any storage facility.

Meanwhile, museum directors say the public will get an unprecedented insight into how the institution's painstaking taxonomic research is carried out. Planned attractions include an 'Explore tour', which will take visitors through selected parts of the collection and labs, and the David Attenborough studio, named after the well-known zoologist and broadcaster, which promises face-to-face interaction with museum staff.

Michael Hopkin 